\title{
Geriatric Assessment, Not ASA Physical Status, Is Associated With 6-Month Postoperative Survival in Patients With Cancer Aged $\geq 75$ Years
}

Armin Shahrokni, MD, MPHa; Bella Marie Vishnevsky, MDº; Brian Jang, BAc; Saman Sarraf, MDa; Koshy Alexander, MDa; Soo Jung Kim, GNPa; Robert Downey, MDd; Anoushka Afonso, MDe; and Beatriz Korc-Grodzicki, MD, PhDa

\section{ABSTRACT}

Background: The American Society of Anesthesiologists physical status (ASA PS) classification system is the most common method of assessing preoperative functional status. Comprehensive geriatric assessment (CGA) has been proposed as a supplementary tool for preoperative assessment of older adults. The goal of this study was to assess the correlation between ASA classification and CGA deficits among oncogeriatric patients and to determine the association of each with 6-month survival. Patients and Methods: Oncogeriatric patients (aged $\geq 75$ years) who underwent preoperative CGA in an outpatient geriatric clinic at a single tertiary comprehensive cancer center were identified. All patients underwent surgery, with a hospital length of stay (LOS) $\geq 1$ day and at least 6 months of follow-up. ASA classifications were obtained from preoperative anesthesiology notes. Preoperative CGA scores ranged from 0 to 13 . Six-month survival was assessed using the Social Security Death Index. Results: In total, 81 of the 980 patients (8.3\%) included in the study cohort died within 6 months of surgery. Most patients were classified as ASA PS III (85.4\%). The mean number of CGA deficits for patients with PS II was 4.03 , PS III was 5.15 , and PS IV was $6.95(P<.001)$. ASA classification was significantly associated with age, preoperative albumin level, hospital LOS, and 30-day intensive care unit (ICU) admissions. On multivariable analysis, 6-month mortality was associated with number of CGA deficits (odds ratio [OR], 1.14 per each unit increase in CGA score; $P=.01$ ), 30-day ICU admissions (OR, 2.77; $P=.003$ ), hospital LOS (OR, 1.03; $P=.02)$, and preoperative albumin level $(O R$, 0.36 ; $P=.004)$. ASA classification was not associated with 6-month mortality. Conclusions: Number of CGA deficits was strongly associated with 6-month mortality; ASA classification was not. Preoperative CGA elicits critical information that can be used to enhance the prediction of postoperative outcomes among older patients with cancer.

J Natl Compr Canc Netw 2019;17(6):687-694 doi: $10.6004 /$ jnccn.2018.7277

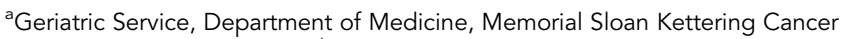
Center, New York, New York; ${ }^{b}$ Department of Anesthesiology, Duke University Hospital, Durham, North Carolina; ' Department of Medicine, Tulane University School of Medicine, New Orleans, Louisiana; and dDepartment of Surgery, and eDepartment of Anesthesiology \& Critical Care, Memorial Sloan Kettering Cancer Center, New York, New York.
}

\section{Background}

For many cancers, surgery remains the primary curative treatment. ${ }^{1-3}$ Geriatric patients experience increased rates of surgical complications compared with younger patients, leading to decreased long-term survival and delayed recovery to preoperative levels of functional independence. ${ }^{4}$ Older patients also face longer hospital stays and higher rates of intensive care unit (ICU) admissions, with the associated adverse effects of delirium, malnutrition, infections, adverse drug effects, and functional decline.$^{2,5,6}$ However, patient age alone is no longer considered sufficient to stratify risk in surgical patients. ${ }^{6,7}$ It is now believed that management of oncogeriatric patients can be improved by performing a preoperative physical fitness assessment and optimizing perioperative care. ${ }^{2}$

The American Society of Anesthesiologists physical status (ASA PS) classification system is widely used in preoperative risk assessment. This system includes 6 classes based on preoperative comorbidities, ${ }^{8-12}$ and these classifications have been shown to accurately stratify most patients by short- and long-term outcomes, including postoperative adverse effects, operative duration, hospital length of stay (LOS), ICU admissions, and survival. ${ }^{8,10-12}$ Furthermore, the ASA system is easy to use and has broad awareness and acceptance. ${ }^{8,9}$ However, its use in the geriatric oncology population has been questioned. In one study of 178 patients aged $\geq 70$ years who underwent elective colorectal surgery, ASA classification was not associated with postoperative complications. ${ }^{5}$ Another study of 460 patients with cancer with a mean age of 76.9 years who underwent breast $(47 \%)$, gastrointestinal (31\%), or genitourinary surgery $(15 \%)$ found that ASA classification $\geq$ PS II was associated with a higher incidence of postoperative major complications (odds ratio [OR], 1.96) but not with hospital LOS or 30-day mortality. ${ }^{13}$

It has been proposed that assessing the fitness level of older patients with cancer preoperatively using a method that elicits additional information may enhance our ability to predict postoperative outcomes, overcome 
the limitations of the ASA classifications, and inform the design of interventions to improve postoperative outcomes. ${ }^{2,14,15}$ One such method is the comprehensive geriatric assessment (CGA), which includes appraisals of physical, cognitive, psychological, and nutritional status; assessment of degree of social support; and review of medications. ${ }^{2,5,13,14,16-19}$ CGA can identify functional impairments that often go undetected by usual physical examination or patient history and can enable accurate risk quantification for severe treatment-related toxicities. Furthermore, deficits in CGA have been shown to correlate with overall survival for patients with many tumor types, ${ }^{20}$ and CGA may elicit information that can inform surgical planning and decision-making. ${ }^{14}$

In this study, we investigated the distribution of ASA classifications among geriatric oncology patients and the prevalence of CGA deficits for each ASA classification. We then compared ASA classification and deficits in CGA domains with 6-month postoperative survival.

\section{Patients and Methods}

This study was approved by the Institutional Review Board at Memorial Sloan Kettering Cancer Center (MSKCC). Older patients with cancer who presented to MSKCC geriatrics clinics for preoperative evaluation between January 2015 and April 2018 underwent CGA. The MSKCC Geriatrics Service performs preoperative evaluation of patients aged $\geq 75$ years. The MSKCC Surgery Services do not currently use a standard frailty screening tool for referral to the Geriatrics Service; referrals are provided based on the surgeon's clinical judgment. Geriatricians and geriatric nurses perform CGAs during preoperative evaluation. Patients who had a CGA performed and then underwent elective surgery that required hospitalization and had at least 6 months of follow-up were included in the final analysis. After surgery, all patients were managed by both the Geriatrics and the Surgery Services.

\section{Measurements}

The CGA instruments performed are listed in Table 1. The cumulative geriatric deficit was calculated as the number of abnormal values out of the 13 evaluated CGA instruments (within 8 domains). The ASA classification includes 6 categories: PS I, normal healthy patients; PS II, patients with mild systemic disease with no functional limitation; PS III, patients with severe systemic disease that leads to functional limitation but not incapacitation; PS IV, patients with incapacitating disease that poses a constant threat to life; PS V, patients who are moribund and not expected to survive beyond 24 hours; and PS VI, patients who are brain-dead and undergoing organ donation. ${ }^{10}$ ASA classification was retrieved from preoperative anesthesiology notes.
Anesthesiologists had access to preoperative notes from the MSKCC Geriatrics Service before they determined ASA classification.

\section{Outcome Variables}

Mortality status was retrieved from the Social Security Death Index. Surgical adverse effects were retrieved from electronic medical records and graded according to the Clavien-Dindo classification system. ${ }^{21}$ In this system, adverse effects are graded based on their severity. A grade $\leq 2$ adverse effect is considered minor, whereas grade $\geq 3$ is considered major. Admissions to the ICU and hospital or visits to the emergency department within 30 days, hospital LOS, and preoperative albumin level were captured from electronic medical records. Other variables assessed preoperatively included sociodemographic characteristics (age, sex, education, marital status) and surgical characteristics (site and duration of surgery, intraoperative blood loss).

\section{Analysis}

Descriptive analysis was performed. Univariable analysis was performed to assess the correlation between ASA classification and sociodemographic characteristics, surgical characteristics, CGA items, number of CGA deficits, and outcomes. Multivariable analysis was performed to assess the relationship between ASA classification and variables significantly $(P<.05)$ associated with ASA classification and 6-month mortality.

\section{Results}

In total, 980 patients were included in the study; 81 patients $(8.3 \%)$ died within 6 months of surgery. Most patients were classified as ASA PS III (85.4\%), 6.6\% were classified as PS II, and $8.0 \%$ were classified as PS IV. Baseline patient characteristics, including demographic characteristics, preoperative albumin level, operative duration, intraoperative blood loss, and hospital LOS, are provided in Table 2 . The most common surgical sites/ procedures were hemicolectomy $(\mathrm{n}=381 ; 33 \%)$, head and neck cancer $(n=242 ; 21 \%)$, gynecologic $(n=229 ; 19.8 \%)$, hepatobiliary and pancreas $(\mathrm{n}=150 ; 13 \%)$, and lung resection ( $\mathrm{n}=150 ; 13 \%)$. Among patients who underwent multiple procedures during the same operation, all procedures were counted $(\mathrm{N}=1,143)$. ASA classification had a statistically significant relationship with age (mean patient age: PS II, 79.12 years; PS III, 80.21 years; PS IV, 83.4 years; $P<.001$ ). The relationship between ASA classification and operative duration was not statistically significant (Table 2).

The relationship between CGA deficits and ASA classification varied among the CGA instruments. Overall, ASA classification was strongly associated with deficits in the functional domains (Figure 1). Higher ASA 


\section{Table 1. Comprehensive Geriatric Assessment Instruments}

\begin{tabular}{|c|c|c|c|}
\hline Domain and Instrument & Description & Scoring & Abnormal Score \\
\hline \multicolumn{4}{|l|}{ Functional status } \\
\hline $\begin{array}{l}\text { Basic activities of daily } \\
\text { living }^{44-46}\end{array}$ & $\begin{array}{l}\text { Level of independence in } 7 \\
\text { activities: bathing, dressing, } \\
\text { grooming, feeding, bladder } \\
\text { control, walking inside the } \\
\text { home, and walking outside the } \\
\text { home }\end{array}$ & $\begin{array}{l}\text { Points scored for each rated } \\
\text { activity } \\
\text { Limited a lot: } 0 \text { points } \\
\text { Limited a little: } 1 \text { point } \\
\text { Not limited at all: } 2 \text { points } \\
\text { Higher scores relate to better } \\
\text { independence }\end{array}$ & $<14$ \\
\hline $\begin{array}{l}\text { Instrumental activities of } \\
\text { daily living }{ }^{47,48}\end{array}$ & $\begin{array}{l}\text { Level of independence in } 8 \\
\text { activities: telephone use, doing } \\
\text { laundry, shopping, preparing } \\
\text { meals, doing housework, } \\
\text { handling own medication, } \\
\text { handling money and finances, } \\
\text { and transportation }\end{array}$ & $\begin{array}{l}\text { Points scored for each rated } \\
\text { activity } \\
\text { Unable to perform the activity: } \\
0 \text { points } \\
\text { Needed some help: } 1 \text { point } \\
\text { Did not need any help: } 2 \text { points } \\
\text { Higher scores relate to better } \\
\text { independence }\end{array}$ & $<16$ \\
\hline $\begin{array}{l}\text { Patient-rated Karnofsky } \\
\text { performance status }{ }^{49}\end{array}$ & Rating of performance status & $\begin{array}{l}\text { Between } 30 \text { and } 100 \text { in } \\
10 \text {-point increments } \\
\text { Higher scores relate to better } \\
\text { performance }\end{array}$ & $\leq 80$ \\
\hline Timed Up and Go test ${ }^{50-52}$ & $\begin{array}{l}\text { Patient is asked to stand from } \\
\text { chair, walk } 10 \text { feet, turn, and } \\
\text { return to chair while timed }\end{array}$ & $\begin{array}{l}<10 \text { seconds } \\
10-19 \text { seconds } \\
\geq 20 \text { seconds }\end{array}$ & $\begin{array}{l}\geq 10 \text { seconds; patients who } \\
\text { were unable to get up from } \\
\text { chair without use of their arms }\end{array}$ \\
\hline Falls & $\begin{array}{l}\text { Total number of falls within the } \\
\text { last year }\end{array}$ & $\begin{array}{l}\text { None } \\
1 \text { time } \\
>1 \text { time }\end{array}$ & $\geq 1$ fall within the last year \\
\hline \multicolumn{4}{|l|}{ Nutrition status } \\
\hline Weight change & $\begin{array}{l}\text { Weight change within past } 6 \\
\text { months }\end{array}$ & $\begin{array}{l}\text { No weight change or weight } \\
\text { gain } \\
<5 \text {-lb weight loss } \\
5 \text { - to } 10 \text {-lb weight loss } \\
10 \text { - to } 20 \text {-lb weight loss }>20 \text {-lb } \\
\text { weight loss }\end{array}$ & $\geq 10$-lb decrease \\
\hline \multicolumn{4}{|l|}{ Polypharmacy } \\
\hline Polypharmacy ${ }^{53}$ & $\begin{array}{l}\text { Total number of prescribed } \\
\text { medications }\end{array}$ & $0,1-4,5-10,>10$ medications & $\geq 5$ medications \\
\hline \multicolumn{4}{|l|}{ Comorbidity ${ }^{\mathrm{a}}$} \\
\hline Comorbid conditions & $\begin{array}{l}\text { The } 13 \text { comorbid conditions of } \\
\text { interest were as follows: } \\
\text { 1. Coronary artery disease, } \\
\text { atrial fibrillation, atrial } \\
\text { flutter, myocardial } \\
\text { infarction, cardiomyopathy, } \\
\text { or heart failure } \\
\text { 2. Dementia, Alzheimer } \\
\text { disease, Lewy body } \\
\text { disease, memory loss, mild } \\
\text { cognitive impairment, or } \\
\text { delirium } \\
\text { 3. Arthritis or degenerative } \\
\text { joint disease } \\
\text { 4. Chronic obstructive } \\
\text { pulmonary disease/asthma } \\
\text { or pneumonia } \\
\text { 5. Cerebrovascular accident } \\
\text { or transient ischemic attack } \\
\text { 6. Diabetes } \\
\text { 7. Hypertension } \\
\text { 8. Kidney failure } \\
\text { 9. Lipid disorders } \\
\text { 10. Liver diseases } \\
\text { 11. Peptic ulcer disorder } \\
\text { 12. Peripheral vascular disease } \\
\text { 13. Thyroid disease }\end{array}$ & 0-13 comorbidities & $\geq 4$ comorbid conditions \\
\hline
\end{tabular}




\section{Table 1. Comprehensive Geriatric Assessment Instruments (cont.)}

\begin{tabular}{|c|c|c|c|}
\hline Domain and Instrument & Description & Scoring & Abnormal Score \\
\hline \multicolumn{4}{|l|}{ Cognition } \\
\hline Mini-Cog ${ }^{54}$ & $\begin{array}{l}\text { Patient asked to recall } 3 \text { words } \\
\text { and perform clock draw test }\end{array}$ & $\begin{array}{l}2 \text { points scored for correct } \\
\text { clock draw } \\
1 \text { point scored for each word } \\
\text { recalled }\end{array}$ & $\leq 2$ \\
\hline \multicolumn{4}{|l|}{ Social support } \\
\hline $\begin{array}{l}\text { 4-item Medical Outcomes } \\
\text { Study: Social Support } \\
\text { Survey }^{55}\end{array}$ & $\begin{array}{l}\text { Four 5-point Likert scale } \\
\text { questionnaire on availability of } \\
\text { emotional/informational, } \\
\text { tangible, affectionate, and } \\
\text { positive social interaction }\end{array}$ & $\begin{array}{l}\text { Score can be } 1-5 \text { points per } \\
\text { item, total score ranges from } 4 \\
\text { to } 20 \\
\text { Higher scores relate to more } \\
\text { social support }\end{array}$ & $\leq 16$ \\
\hline \multicolumn{4}{|l|}{ Social activity interference } \\
\hline $\begin{array}{l}\text { Medical Outcomes Study: } \\
\text { Social Activity Survey }{ }^{56}\end{array}$ & $\begin{array}{l}\text { Three 5-point Likert scale } \\
\text { questionnaire on the } \\
\text { interference of patient's health } \\
\text { condition with the social } \\
\text { activity }\end{array}$ & $\begin{array}{l}\text { Score can be } 1-5 \text { points per } \\
\text { item, total score ranges from } 3 \\
\text { to } 15 \\
\text { Higher scores relate to higher } \\
\text { social activity }\end{array}$ & $\geq 8$ \\
\hline \multicolumn{4}{|l|}{ Emotional status } \\
\hline $\begin{array}{l}\text { 4-item geriatric depression } \\
\text { scale }^{57}\end{array}$ & $\begin{array}{l}\text { 4-item yes/no questionnaire of } \\
\text { patient's psychologic status }\end{array}$ & 1 point per question & Score $\geq 1$ \\
\hline Distress Thermometer ${ }^{58-62}$ & $\begin{array}{l}\text { Patient asked to rate distress } \\
\text { level in last } 2 \text { weeks }\end{array}$ & $\begin{array}{l}\text { Between } 10 \text { (extreme distress) } \\
\text { and } 0 \text { (no distress) }\end{array}$ & Score $\geq 4$ \\
\hline
\end{tabular}

${ }^{a}$ Comorbid conditions were captured by ICD-9/10 codes of the claims submitted within the first 24 hours of hospital stay.

classification was significantly associated with higher rates of impairment in basic activities of daily living, instrumental activities of daily living, patient-rated Karnofsky performance status, and Timed Up and Go test. ASA classification was also significantly associated with polypharmacy and increased number of comorbid conditions. However, ASA classification was not associated with social support, distress, or cognitive status (Figure 1). Across the 13 instruments evaluated, higher ASA classification was associated with higher number of deficits per patient (mean deficits per patient: PS II, 4.03; PS III, 5.15; PS IV, 6.95; $P<.001$ ) (Figure 1).

ASA classification was significantly associated with 30-day ICU admission (proportion of patients admitted to the ICU within 30 days: PS II, 3.1\%; PS III, 5.0\%; PS IV, $11.5 \%$; $P=.03$ ). However, ASA classification was not associated with several other measures, including 30-day hospital readmission, 30-day emergency department visit, and minor or major adverse events (Table 3). ASA classification was also not associated with 6-month mortality (PS II, 9.2\%; PS III, 7.9\%; PS IV, 11.5\%; $P=.51$ ).

On multivariable analysis that compared ASA classification and number of geriatric deficits with 6-month mortality, number of geriatric deficits was strongly associated with higher risk of 6 -month mortality (OR, 1.14; $P=.01)$; risk of 6 -month mortality did not differ significantly between ASA PS III or PS IV versus PS II (PS III: OR, 0.86 ; $P=.81$; PS IV: OR, $0.44 ; P=.30$ ). Thirty-day ICU admission (OR, 2.77; $P=.03$ ), hospital LOS (OR, 1.03; $P=.02$ ), and preoperative albumin level $(\mathrm{OR}, 0.36 ; P=.004)$ were also associated with 6-month mortality (Table 4).

\section{Discussion}

This study investigated the distribution of ASA classifications and the prevalence of CGA deficits for each ASA classification among patients with cancer aged $\geq 75$ years. ASA classification and number of CGA deficits were also compared with 6-month mortality. Among the study patients, $>85 \%$ were classified as ASA PS III. Higher ASA classification was associated with deficits in patientrated Karnofsky performance status, basic activities of daily living, instrumental activities of daily living, Timed Up and Go test, polypharmacy, and multiple comorbid conditions. ASA classification was not associated with 6-month mortality. However, for each added geriatric deficit, 6-month mortality increased by $14 \%(P=.01)$ despite adjustment for age, ICU admissions, hospital LOS, and preoperative albumin level.

Literature on the relationship between ASA classification and postoperative survival suggests there is a strong correlation. Hamel et $\mathrm{al}^{22}$ investigated a large cohort of patients aged $>80$ years enrolled in the Veterans Affairs National Surgical Quality Improvement Project who underwent noncardiac surgery $(\mathrm{N}=26,648)$ and concluded that ASA classification was strongly associated with survival (OR, 1.9; $P<.001)$. Other groups have found that ASA classification correlates with survival among geriatric patients with colorectal cancer (hazard ratio $[\mathrm{HR}], 2.72$; 
Table 2. Sociodemographic and Surgical Characteristics of the Study Cohort

\begin{tabular}{|c|c|c|c|c|c|}
\hline Characteristic & $\begin{array}{l}\text { Whole Cohort } \\
\qquad(\mathrm{N}=980)\end{array}$ & $\begin{array}{c}\text { ASA PS II } \\
(n=65 ; 6.6 \%)\end{array}$ & $\begin{array}{c}\text { ASA PS III } \\
(n=837 ; 85.4 \%)\end{array}$ & $\begin{array}{c}\text { ASA PS IV } \\
(n=78 ; 8.0 \%)\end{array}$ & $P$ Value \\
\hline Mean age (SD), y & $80.39(4.3)$ & $79.12(3.7)$ & $80.21(4.2)$ & $83.47(5.0)$ & $<.001$ \\
\hline Married, n (\%) & $548(56.1 \%)$ & $33(50.8 \%)$ & $475(56.7 \%)$ & $40(51.3 \%)$ & .48 \\
\hline College graduate or higher, $\mathrm{n}(\%)$ & $448(45.9 \%)$ & $36(55.4 \%)$ & $377(45.0 \%)$ & 35 (44.8\%) & .23 \\
\hline Mean hospital length of stay (SD), d & $7.20(8.2)$ & $7.06(8.1)$ & $7.03(8.2)$ & $9.17(8.5)$ & .09 \\
\hline Mean intraoperative blood loss (SD), mm & $225(351)$ & $215(247)$ & $228(352)$ & $196(416)$ & .76 \\
\hline
\end{tabular}

Abbreviation: ASA PS, American Society of Anesthesiologists physical status.

$P=.023)^{23}$ and head and neck cancer $(\mathrm{HR}, 2.1 ; P<.005) .{ }^{24}$ However, in our study, ASA classification was not associated with 6-month survival. One reason for this may be the large patient volume seen at MSKCC, a comprehensive cancer center specializing in cancer surgeries. Lower rates of mortality and improved outcomes have been correlated with high surgical volume in studies spanning decades. ${ }^{25-27}$ As a result, the association between ASA classification and outcomes may be less pronounced at tertiary care hospitals than at other places. Another possible explanation for such a finding is the distribution of ASA classifications in our cohort, with most patients categorized as ASA PS III-the use of additional methods may have resulted in better stratification.

ASA classification was not significantly associated with hospital LOS, 30-day emergency department visit, 30-day readmission, or minor and major adverse events. Failure to find such a correlation could be attributable to our postoperative care process for geriatric oncology patients. ${ }^{28}$ We perform CGA and management in the preoperative period, and patients are co-managed by the MSKCC Geriatrics and Surgery Services in the postoperative period. This intervention paradigm has been shown to improve outcomes of older patients, especially after orthopedic surgery. ${ }^{29}$ In addition, a perioperative program that includes multiple care pathways-known as enhanced recovery after surgery (ERAS) - has been implemented by many surgical departments at MSKCC. ERAS has been associated with shorter hospital LOS, lower morbidity, and reduced readmission rates, ${ }^{30-32}$ and this might be at least partially responsible for the lack of correlation between ASA classification and outcomes in the present study.

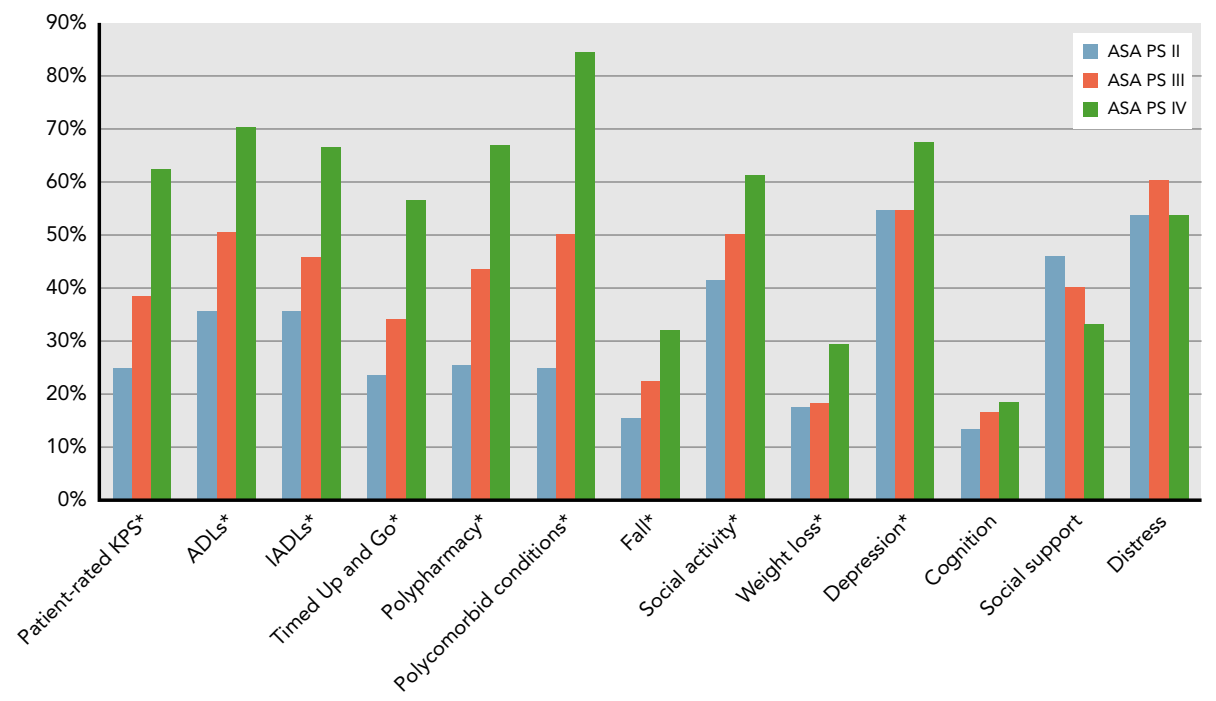

Figure 1. Comprensive geriatric assessment deficits and ASA PS classifications.

Abbreviations: ADLs, activities of daily living; ASA PS, American Society of Anesthesiologists physical status; iADLs, instrumental ADLs; KPS, Karnofsky performance status.

${ }^{\star} P<.05$. 
Table 3. Adverse Events by ASA PS Classification

\begin{tabular}{|c|c|c|c|c|c|}
\hline Adverse Event & $\begin{array}{c}\text { Whole Cohort } \\
\text { n (\%) }\end{array}$ & $\begin{array}{c}\text { ASA PS II } \\
\text { n (\%) }\end{array}$ & $\begin{array}{c}\text { ASA PS III } \\
\text { n (\%) }\end{array}$ & $\begin{array}{c}\text { ASA PS IV } \\
\text { n (\%) }\end{array}$ & $P$ Value \\
\hline Total, N & 980 & 65 & 837 & 78 & \\
\hline 30-day hospital readmission & 83 (8.5\%) & $5(7.7 \%)$ & 69 (8.2\%) & 9 (11.7\%) & .16 \\
\hline 30-day ED visit & $121(12.4 \%)$ & $6(9.2 \%)$ & $103(12.3 \%)$ & $12(15.6 \%)$ & .50 \\
\hline 6-month mortality & 81 (8.3\%) & $6(9.2 \%)$ & 66 (7.9\%) & 9 (11.5\%) & .51 \\
\hline
\end{tabular}

Abbreviations: ASA PS, American Society of Anesthesiologists physical status; ED, emergency department; ICU, intensive care unit.

Number of geriatric deficits, after adjustment for ASA classification, was strongly associated with postoperative 6 -month survival. Accumulating evidence confirms that CGA is a valid tool for prediction of survival in the oncogeriatric population. Geriatric markers of frailty, including functional deficits, have been found to be associated with mortality, hospital LOS, and likelihood of discharge to a nursing facility. ${ }^{33,34}$ In our experience, performing preoperative CGA and postoperative geriatric comanagement is feasible as routine care. ${ }^{35}$ However, a 2016 survey of surgeons' attitudes, conducted by the International Society of Geriatric Oncology, found that only $6.4 \%$ of respondents performed geriatric assessment routinely. ${ }^{36}$ One possible barrier to implementation of CGA in perioperative settings could be the time required to complete such assessments. Preoperative assessment of cancer in the elderly-a CGA for the assessment of oncogeriatric surgical fitness that has been shown to predict postoperative adverse effects and hospital LOS-requires 20 minutes to complete. ${ }^{13}$ Increased interest in properly assessing older adults in preoperative settings led investigators to develop a range of screening

\begin{tabular}{|lccc|}
\hline $\begin{array}{l}\text { Table 4. Multivariable Regression Analysis of } \\
\text { ASA PS Classification and Variables } \\
\text { Significantly Associated With ASA } \\
\text { Classification Versus }\end{array}$ \\
\hline 6-Month Mortality \\
\hline Variable & Odds Ratio & $\mathbf{9 5 \%}$ Cl & P Value \\
\hline ASA PS III & 0.86 & $0.24-2.99$ & .81 \\
\hline Age & 0.44 & $0.09-2.10$ & .30 \\
\hline Number of geriatric deficits & 1.05 & $0.99-1.11$ & .08 \\
\hline 30-day ICU admission & 1.14 & $1.02-1.26$ & .01 \\
\hline Hospital length of stay & 2.77 & $1.06-7.24$ & .03 \\
\hline Preoperative albumin level & 1.03 & $1.005-1.067$ & .02 \\
\hline
\end{tabular}

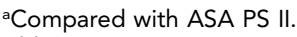

Abbreviations: ASA PS, American Society of Anesthesiologists physical status; $I C U$, intensive care unit. tools to detect frailty in patients with cancer. ${ }^{28,36,37}$ CGAbased screening tools such as the G8 and the Vulnerable Elders Survey (VES-13) attempt to leverage improved detection of frailty to ensure appropriate medical care planning in accordance with the patient's preoperative risk. ${ }^{13,15,38-40}$ G8 and VES-13 can be completed in as little as 5 minutes. ${ }^{40}$ CGA remains the most widely recognized assessment method for the care and treatment planning of geriatric patients. ${ }^{36}$ At MSKCC, the Electronic Rapid Fitness Assessment is routinely administered by the Geriatrics Service, enabling patient-reported assessments to be completed online before the preoperative appointment, which can reduce the completion time in clinic to 11 minutes. ${ }^{28}$ Some practitioners have argued that the time spent administering the CGA is more than reasonable, considering that the information can be used to estimate survival and assess the risks of treatmentrelated adverse effects. ${ }^{41}$ The overall reduction in assessment completion times reported recently ${ }^{42}$ and the best practice guidelines for proper preoperative assessment of older patients ${ }^{43}$ have, in our experience, increased interest in the adoption and expanding use of CGA in surgical oncology clinics.

This study has several limitations. Because all patients in the study cohort were from a single institution, excluding emergency surgical cases, our results may not be generalizable; therefore, studies comparing CGA deficits with ASA classification should be performed at other institutions or in a multi-institutional setting. In addition, patients aged $\geq 75$ years who were not referred to the Geriatrics Service preoperatively and did not have a CGA performed were not included in the study. The study cohort included only patients who underwent preoperative evaluation (and CGA) by a geriatrician, followed by postoperative geriatric comanagement. Although we have not assessed the use of supportive services (eg, physical therapy) in the postoperative period, especially for patients with more geriatric deficits, it is likely that our interventions actually weakened the relationship between geriatric deficits and 6-month survival among 
these patients. In the future, we plan to elaborate on the use and impact of supportive services for patients who are comanaged by the Geriatrics Service compared with those who do not receive geriatric comanagement. Moreover, our mortality data were retrieved from the Social Security Death Index, and therefore this study is limited by not differentiating between cancer-related and non-cancer-related causes of mortality. Similarly, we did not have data on neoadjuvant or adjuvant chemotherapy and/or radiation. We selected 6-month mortality as a relatively short-term outcome to reduce the degree of limitation that these issues pose for our study finding.

This study also has several strengths. It is one of the largest studies of patients with cancer aged $\geq 75$ years who have undergone surgery. All patients in our study underwent CGA. Although the single-institution nature of the study limits the generalizability of our findings, this design reduces the influence of variability in postoperative care processes, resources, and surgeon experiences among different institutions on 6-month mortality.

\section{Conclusions}

In our cohort of patients with cancer aged $\geq 75$ years, ASA classification, despite a strong relationship with multiple CGA deficits, was not associated with 6-month postoperative mortality. However, CGA was strongly associated with 6-month mortality and can be a useful tool for surgical decision-making for these patients.

\section{Acknowledgments}

The authors wish to thank all older patients with cancer and their families who completed the assessment during preoperative evaluation. Moreover, the authors appreciate the great effort by the geriatric registered nurses and nurse practitioners. Finally, the authors thank Mr. David Sewell for assistance with the manuscript.

\section{Submitted October 11, 2018; accepted for publication January 17, 2019}

Previous presentation: This study was presented in part at the 16 th Annual Conference of the International Society of Geriatric Oncology; November 17-19, 2016; Milan, Italy.

Author contributions: Study concept and design: Shahrokni. Data acquisition and quality control: Shahrokni, Sarraf. Data analysis and interpretation: Shahrokni, Vishnevsky, Jang, Alexander, Korc-Grodzicki, Downey, Afonso. Statistical analysis: Shahrokni. Drafting of manuscript: All authors. Critical revisions: All authors.

Disclosures: The authors have not received any financial consideration from any person or organization to support the preparation, analysis, results, or discussion of this article.

Funding: Research reported in this publication was supported, in part, by the Beatriz and Samuel Seaver Foundation, the Memorial Sloan Kettering Cancer and Aging Program, and $\mathrm{NIH} / \mathrm{NCl}$ Cancer Center Support Grants (P30CA008748 and R25CA020449).

Disclaimer: The content is solely the responsibility of the authors and does not necessarily represent the official views of the NIH.

Correspondence: Armin Shahrokni, MD, MPH, Geriatric Service, Department of Medicine, Memorial Sloan Kettering Cancer Center, Box 205, 1275 York Avenue, New York, NY 10065. Email: shahroka@mskcc.org

\section{References}

1. Audisio RA, Veronesi P, Ferrario L, et al. Elective surgery for gastrointestinal tumours in the elderly. Ann Oncol 1997;8:317-326.

2. Korc-Grodzicki B, Downey RJ, Shahrokni A, et al. Surgical considerations in older adults with cancer. J Clin Oncol 2014;32:2647-2653.

3. Kelly E, Stephens P. Cancer in the older person. Rev Clin Gerontol 2015; 25:172-180.

4. Lawrence VA, Hazuda HP, Cornell JE, et al. Functional independence after major abdominal surgery in the elderly. J Am Coll Surg 2004;199: 762-772.

5. Kristjansson SR, Nesbakken A, Jordhøy MS, et al. Comprehensive geriatric assessment can predict complications in elderly patients after elective surgery for colorectal cancer: a prospective observational cohort study. Crit Rev Oncol Hematol 2010;76:208-217.

6. Marusch F, Koch A, Schmidt U, et al. The impact of the risk factor "age" on the early postoperative results of surgery for colorectal carcinoma and its significance for perioperative management. World J Surg 2005;29: 1013-1021.

7. Inedioha U, Gravante G, Lloyd G, et al. Curative colorectal resections in patients aged 80 years and older: clinical characteristics, morbidity, mortality and risk factors. Int J Colorectal Dis 2013;28:941-947.

8. Daabiss M. American Society of Anaesthesiologists physical status classification. Indian J Anaesth 2011;55:111-115.

9. Ranta S, Hynynen M, Tammisto T. A survey of the ASA physical status classification: significant variation in allocation among Finnish anaesthesiologists. Acta Anaesthesiol Scand 1997;41:629-632.

10. Sankar A, Johnson SR, Beattie WS, et al. Reliability of the American Society of Anesthesiologists physical status scale in clinical practice. $\mathrm{Br} \mathrm{J}$ Anaesth 2014;113:424-432.

11. Menke $H$, Klein A, John KD, et al. Predictive value of ASA classification for the assessment of the perioperative risk. Int Surg 1993;78:266-270.
12. Wolters $U$, Wolf $T$, Stützer $H$, et al. ASA classification and perioperative variables as predictors of postoperative outcome. Br J Anaesth 1996;77: 217-222.

13. Audisio RA, Pope D, Ramesh HS, et al. Shall we operate? Preoperative assessment in elderly cancer patients (PACE) can help. A SIOG surgical task force prospective study. Crit Rev Oncol Hematol 2008;65:156-163.

14. Knittel JG, Wildes TS. Preoperative assessment of geriatric patients. Anesthesiol Clin 2016;34:171-183.

15. Souwer ETD, Verweij NM, van den Bos F, et al. Risk stratification for surgical outcomes in older colorectal cancer patients using ISAR-HP and G8 screening tools. J Geriatr Oncol 2018;9:110-114.

16. Extermann M. Geriatric oncology: an overview of progresses and challenges. Cancer Res Treat 2010;42:61-68.

17. Mohile SG, Velarde C, Hurria A, et al. Geriatric assessment-guided care processes for older adults: a Delphi consensus of geriatric oncology experts. J Natl Compr Canc Netw 2015;13:1120-1130.

18. Extermann M, Aapro M, Bernabei R, et al. Use of comprehensive geriatric assessment in older cancer patients: recommendations from the task force on CGA of the International Society of Geriatric Oncology (SIOG). Crit Rev Oncol Hematol 2005;55:241-252.

19. Stuck $A E$, Siu AL, Wieland GD, et al. Comprehensive geriatric assessment: a meta-analysis of controlled trials. Lancet 1993;342:1032-1036.

20. Wildiers $H$, Heeren P, Puts $M$, et al. International Society of Geriatric Oncology consensus on geriatric assessment in older patients with cancer. J Clin Oncol 2014;32:2595-2603.

21. Clavien PA, Barkun J, de Oliveira ML, et al. The Clavien-Dindo classification of surgical complications: five-year experience. Ann Surg 2009;250:187-196.

22. Hamel MB, Henderson WG, Khuri SF, et al. Surgical outcomes for patients aged 80 and older: morbidity and mortality from major noncardiac surgery. J Am Geriatr Soc 2005;53:424-429. 
23. Kim YW, Kim IY. Factors associated with postoperative complications and 1 -year mortality after surgery for colorectal cancer in octogenarians and nonagenarians. Clin Interv Aging 2016;11:689-697.

24. Riechelmann $\mathrm{H}$, Neagos A, Netzer-Yilmaz U, et al. Der ASA-Score als Komorbiditätsindex bei Mundhöhlen- und Mundrachenkarzinomen [The ASA-score as a comorbidity index in patients with cancer of the oral cavity and oropharynx]. Laryngorhinootologie 2006;85:99-104.

25. Begg CB, Cramer LD, Hoskins WJ, et al. Impact of hospital volume on operative mortality for major cancer surgery. JAMA 1998;280:1747-1751.

26. Birkmeyer JD, Siewers AE, Finlayson EV, et al. Hospital volume and surgical mortality in the United States. N Engl J Med 2002;346:1128-1137.

27. Dudley RA, Johansen KL, Brand R, et al. Selective referral to high-volume hospitals: estimating potentially avoidable deaths. JAMA 2000;283: 1159-1166.

28. Shahrokni A, Kim SJ, Bosl GJ, et al. How we care for an older patient with cancer. J Oncol Pract 2017;13:95-102.

29. Grigoryan KV, Javedan H, Rudolph JL. Orthogeriatric care models and outcomes in hip fracture patients: a systematic review and meta-analysis. J Orthop Trauma 2014;28:e49-55.

30. Afonso A, Dayan J, Oskar S. ERAS implementation in breast reconstructive surgery: which elements are important? Clin Nutr ESPEN 2016;12:e37.

31. Azhar RA, Bochner B, Catto J, et al. Enhanced recovery after urological surgery: a contemporary systematic review of outcomes, key elements, and research needs. Eur Urol 2016;70:176-187.

32. Varadhan $\mathrm{KK}, \mathrm{Neal} \mathrm{KR}$, Dejong $\mathrm{CH}$, et al. The enhanced recovery after surgery (ERAS) pathway for patients undergoing major elective open colorectal surgery: a meta-analysis of randomized controlled trials. Clin Nutr 2010;29:434-440.

33. Kim SW, Han HS, Jung HW, et al. Multidimensional frailty score for the prediction of postoperative mortality risk. JAMA Surg 2014;149:633-640.

34. Robinson TN, Eiseman B, Wallace JI, et al. Redefining geriatric preoperative assessment using frailty, disability and co-morbidity. Ann Surg 2009;250:449-455.

35. Korc-Grodzicki B, Sun SW, Shahrokni A, et al. The role of a geriatrician in a cancer center [abstract]. J Clin Oncol 2016;34(Suppl):Abstract 39.

36. Ghignone F, van Leeuwen BL, Montroni I, et al. The assessment and management of older cancer patients: a SIOG surgical task force survey on surgeons' attitudes. Eur J Surg Oncol 2016;42:297-302.

37. Shahrokni A, Tin A, Downey RJ, et al. Electronic Rapid Fitness Assessment: a novel tool for preoperative evaluation of the geriatric oncology patient. J Natl Compr Canc Netw 2017;15:172-179.

38. Martinez-Tapia C, Paillaud E, Liuu E, et al. Prognostic value of the G8 and modified-G8 screening tools for multidimensional health problems in older patients with cancer. Eur J Cancer 2017;83:211-219.

39. Petit-Monéger $A$, Rainfray $M$, Soubeyran $P$, et al. Detection of frailty in elderly cancer patients: improvement of the G8 screening test. J Geriatr Oncol 2016;7:99-107.

40. Soubeyran P, Bellera C, Goyard J, et al. Screening for vulnerability in older cancer patients: the ONCODAGE Prospective Multicenter Cohort Study. PLoS One 2014;9:e115060.

41. Hamaker ME, Wildes TM, Rostoft S. Time to stop saying geriatric assessment is too time consuming. J Clin Oncol 2017;35:2871-2874.

42. Liu JJ, Extermann M. Comprehensive geriatric assessment and its clinical impact in oncology. Clin Geriatr Med 2012;28:19-31.
43. Chow WB, Rosenthal RA, Merkow RP, et al. Optimal preoperative assessment of the geriatric surgical patient: a best practices guideline from the American College of Surgeons National Surgical Quality Improvement Program and the American Geriatrics Society. J Am Coll Surg 2012;215:453-466.

44. Hartigan I. A comparative review of the Katz ADL and the Barthel Index in assessing the activities of daily living of older people. Int J Older People Nurs 2007;2:204-212.

45. Katz S, Downs TD, Cash HR, et al. Progress in development of the index of ADL. Gerontologist 1970;10:20-30.

46. Katz S, Ford AB, Moskowitz RW, et al. Studies of illness in the aged. The index of ADL: a standardized measure of biological and psychosocial function. JAMA 1963;185:914-919.

47. Hoppe $S$, Rainfray M, Fonck $M$, et al. Functional decline in older patients with cancer receiving first-line chemotherapy. J Clin Oncol 2013;31:3877-3882.

48. Lawton MP, Brody EM. Assessment of older people: self-maintaining and instrumental activities of daily living. Gerontologist 1969;9:179-186.

49. Mor V, Laliberte L, Morris JN, et al. The Karnofsky performance status scale. An examination of its reliability and validity in a research setting Cancer 1984;53:2002-2007.

50. Guideline for the prevention of falls in older persons. American Geriatrics Society, British Geriatrics Society, and American Academy of Orthopaedic Surgeons Panel on Falls Prevention. J Am Geriatr Soc 2001;49:664-672.

51. Bohannon RW. Reference values for the timed up and go test: a descriptive meta-analysis. J Geriatr Phys Ther 2006;29:64-68.

52. Yeung TS, Wessel J, Stratford PW, et al. The timed up and go test for use on an inpatient orthopaedic rehabilitation ward. J Orthop Sports Phys Ther 2008;38:410-417.

53. Gnjidic D, Hilmer SN, Blyth FM, et al. Polypharmacy cutoff and outcomes: five or more medicines were used to identify community-dwelling older men at risk of different adverse outcomes. J Clin Epidemiol 2012;65:989-995.

54. Borson S, Scanlan J, Brush M, et al. The mini-cog: a cognitive 'vital signs' measure for dementia screening in multi-lingual elderly. Int J Geriatr Psychiatry 2000;15:1021-1027.

55. Gjesfjeld CD, Greeno CG, Kim KH. A confirmatory factor analysis of an abbreviated social support instrument: the MOS-SSS. Res Soc Work Pract 2008;18:231-237.

56. Stewart A, Ware JE. Measuring Functioning and Well-Being: The Medical Outcomes Study Approach. Durham, NC: Duke University Press; 1992.

57. Pomeroy IM, Clark CR, Philp I. The effectiveness of very short scales for depression screening in elderly medical patients. Int J Geriatr Psychiatry 2001;16:321-326.

58. Hegel MT, Collins ED, Kearing S, et al. Sensitivity and specificity of the Distress Thermometer for depression in newly diagnosed breast cancer patients. Psychooncology 2008;17:556-560.

59. Roth AJ, Komblith AB, Batel-Copel L, et al. Rapid screening for psychologic distress in men with prostate carcinoma: a pilot study. Cancer 1998;82:1904-1908.

60. Mitchell AJ. Pooled results from 38 analyses of the accuracy of distress thermometer and other ultra-short methods of detecting cancer-related mood disorders. J Clin Oncol 2007;25:4670-4681.

61. Ransom S, Jacobsen PB, Booth-Jones M. Validation of the Distress Thermometer with bone marrow transplant patients. Psychooncology 2006;15:604-612.

62. Holland JC, Bultz BD. The NCCN Guideline for distress management: a case for making distress the sixth vital sign. J Natl Compr Canc Netw 2007;5:3-7. 